\title{
Preparation of Scaffolds of Amorphous Calcium Phosphate and Bacterial Cellulose for Use in Tissue Regeneration by Freeze-Drying Process
}

\author{
Olinka Tiomno Tiomnova ${ }^{1}(\mathbb{D})$, Fernanda Coelho ${ }^{2}$ (D), Thales A. Garcia Pellizaro ${ }^{3}$ (D), Jorge Enrique \\ Rodriguez Chanfrau ${ }^{3, *}{ }^{(D)}$, Ticiana Sidorenko de Oliveira Capote ${ }^{2(\mathbb{D}}$, Pierre Basmaji ${ }^{4}{ }^{\mathbb{D}}$, Yaymarilis \\ Veranes Pantoja ${ }^{5}$ (D), Antonio Carlos Guastaldi ${ }^{3}$ (D) \\ Center of Engineering and Chemical Investigations. Havana. CP 10600, Cuba \\ São Paulo State University (UNESP), School of Dentistry, Department of Morphology, Araraquara, SP, 14801-903. Brazil \\ Group of Biomaterials, Department of Physical Chemistry, Institute of Chemistry, Sao Paulo State University (UNESP), \\ Araraquara, SP, 14800-060, Brazil \\ 4 Innovatec's - Biotechnology Research and Development, São Carlos-SP, Brazil \\ 5 Center of Biomaterials, University of Havana. Vedado, La Habana. Cuba \\ * Correspondence: jerodriguez354@gmail.com;
}

Scopus Author ID 7801488065

Received: 16.05.2020; Revised: 12.06.2020; Accepted: 14.06.2020; Published: 16.06.2020

\begin{abstract}
The elaboration of scaffolds for use in tissue regeneration processes plays an important role in the area of biomaterials. Natural and synthetic polymers, together with calcium phosphates, form suitable compounds for these studies because their combinations favor the union of the properties of both materials, such as their biocompatibility, biofunctionality, shape, porosity, and mechanical properties. The objective of this work was to develop a scaffold of amorphous calcium phosphate and bacterial cellulose, applying a freeze-drying process. The results demonstrated the feasibility of scaffolds elaboration applying the freeze-drying methodology. The formulation that presented the best results was the one that contained amorphous calcium phosphate (50\%), bacterial cellulose gel (20\%), and sodium alginate (30\%). Cytotoxicity studies showed that the studied formulation did not present cytotoxicity, promoting cell viability.
\end{abstract}

Keywords: Biomaterials; Calcium phosphates, Scaffolds, Freeze-drying, Cytotoxicity study.

(C) 2020 by the authors. This article is an open-access article distributed under the terms and conditions of the Creative Commons Attribution (CC BY) license (https://creativecommons.org/licenses/by/4.0/).

\section{Introduction}

The aging of the population, together with the increase in the expectation and quality of life, has increased the development of biomaterials to be used in tissue regeneration. Bone tissue has a limited capacity for regeneration, depending on the size of the lesion, so the development of new types of treatments to be used in regeneration processes is an area of science that has a high social impact [1-3].

Among the methodologies currently applied in the field of tissue regeneration, is the development of Scaffolds made with biomaterials. Scaffolds are three-dimensional structures designed to support cell infiltration, growth, and differentiation, with the aim of improving the development and formation of new tissues [4-7].

These structures must be biodegradable over time, being one of the fundamental characteristics to be guaranteed during their development. That is why it is essential to define the biomaterials to be used during the manufacturing process $[4,5,8,9]$. Biomaterials that have 
good biocompatibility, an adequate rate of degradation, and physical, chemical, and mechanical properties are the optimal ones to guarantee the obtaining of a Scaffold with the quality necessary to be used in biological systems $[8,9,10]$.

There are different methodologies for the elaboration of a scaffold. Some authors classify these methodologies into two main groups: Conventional (freeze-drying, leaching techniques, foam formation, phase separation, fiber formation, among others) and advanced (selective sintering by laser, stereolithography, deposition of molten material, inkjet printing and three-dimensional printing - 3D) [11-15]. Freeze-drying is a methodology conventional used for making scaffold and consists of a dehydration process where the material is frozen at low temperatures and subsequently removed by sublimation water using a technique known as lyophilization [16, 17].

Among the biomaterials used in tissue regeneration are calcium phosphates and bacterial cellulose [18-25]. The objective of this work was to develop a scaffold of amorphous calcium phosphate and bacterial cellulose, applying a freeze-drying process.

\section{Materials and Methods}

Amorphous calcium phosphate (ACP) was synthesized by applying the methodology described by Debone et al. [18]. Later it was ground and sieved. Material with a particle size of less than $74 \mu \mathrm{m}$ was used in this study. Innovatecs Productos Biotecnológicos LTDA, São Carlos - São Paulo, Brazil, supplied bacterial cellulose gel.

\subsection{Ink preparation procedure.}

Two concentrations of sodium alginate (20\% and 30\%) were studied. The sodium alginate was dispersed in $100 \mathrm{~mL}$ of water. Subsequently, the amounts of bacterial cellulose gel (equivalent to $10 \%$ ), amorphous calcium phosphate (equivalent to $50 \%$ ), and 500 microliters of tween were added.

The mixture was homogenized for 30 minutes at a speed of $350 \mathrm{rpm}$ using a mechanical stirrer. The inks obtained were divided into two parts. A part was evaluated by determining the viscosity at the beginning and 7 days after elaboration. The other part was placed in a mold (diameter of $1 \mathrm{~cm}$ and height of $5 \mathrm{~cm}$ ) and freeze-dried for 48 hours. The scaffolds obtained were named Cart 1 and Cart 2. A study to determine the content of absorbed water and the loss of mass during a study of the influence of humidity was carried out. In parallel, they were evaluated through a cytotoxicity study. The scaffold that presented the best result was chosen to continue the studies.

Once the concentration of sodium alginate was established, the appropriate concentration of bacterial cellulose in the formulation was determined. Three concentrations of bacterial cellulose $(10 \%, 20 \%$, and $30 \%)$ were studied. The amorphous calcium phosphate concentration was maintained at $50 \%$.

The elaborate inks were divided into two parts. With one of the parts, the viscosity was evaluated at the beginning and 30 days. While with the other part, the scaffold was made by freeze-dried and the Shore A hardness was determined.

With the selected variant, the Scaffolds were made by freeze-drying and characterized by Scanning electron microscopy (MEV) and Electron dispersive spectroscopy (EDS), determination of surface area, and porosity, mechanical test and cytotoxicity test. 


\subsection{Characterization.}

The viscosity was determined on a Haake concentric cylinder viscometer (model $\mathrm{RV} 20$ ), which is coupled with the M5/NV system. The evaluation was made at $25 \pm 0.1^{\circ} \mathrm{C}$. A velocity gradient between 0 and $100 \mathrm{~s}-1$ and shear stress of 0 to $200 \mathrm{~Pa}$ were used. The measurements were made in triplicate.

Shore A hardness was determined in accordance with ASTM D2240 (ASTM D2240 15. Standard Test Method for Rubber Property-Durometer Hardness). A Metrotokyo durometer (Japan) was used. The test was performed with a weight of $1 \mathrm{kgf}$ and a penetration time of $1 \mathrm{~s}$. The experiment was carried out in three different points, calculating the mean and standard deviation.

The study of the influence of humidity was carried out according to ISO 6270-2 (ISO 6270-2:2017. Paints and varnishes - Determination of resistance to humidity - Part 2: Condensation in-cabinet exposure with heated water reservoir). A Hygrotherm 519 humidity chamber (ERICHSEN, Germany) was used. The samples were placed at $100 \%$ relative humidity and $37^{\circ} \mathrm{C}$ for $24 \mathrm{~h}$. They were weighed at the beginning (initial weight) and after 24 $\mathrm{h}$ (wet weight). Subsequently, they were dried at the constant weight at $80{ }^{\circ} \mathrm{C}$ and weighed (final weight). The determination of the absorbed water content and the loss of mass was calculated according to Sandonis [26].

The morphology samples were investigated by Scanning Electron Microscopy (SEM) in a JEOL microscopy model JSM-7500F equipped with an X-ray energy dispersive spectroscopy detector (EDS). The EDS counting time was $20000 \mathrm{~s}$ per analysis at an acceleration voltage of $10 \mathrm{kV}$.

The determination of surface area and porosity were determined according to Rodriguez Chanfrau et al., [19]. Nitrogen Absorption/desorption isotherms were obtained using a Micromeritics ASAP 2010 (Micromeritics Instrument Corp. USA). The measurements were performed to $76.8 \mathrm{~K}$ (Araraquara, Brazil), using or static volumetric method and relative pressure between 0.002 and 0,998 intervals. Prior to the experimental runs of N2 sorption, each sample was degassed for 60 minutes under a vacuum of 10-6 Torr.

The mechanical compression resistance test (Emic DL2000, Tesc Program 384) was performed with a $2 \mathrm{kN}$ Trd 28 load cell, using a speed of $1 \mathrm{~mm} / \mathrm{min}$, in accordance with ISO 5833 standards. Six samples were evaluated in the experiment. The compressive strengths of the samples were calculated as the maximum applied force divided by the loaded area. The reported compressive strength values are the average values of the six measurements, each taken with a single sample to capture variations in the manufacturing process.

\subsection{Biological test.}

\subsubsection{Cell culture experiments.}

Chinese hamster ovary cells (CHO-K1) were grown in 1:1 Ham-F10+D-MEM (Sigma ${ }^{\circledR}$, St. Louis, MO) culture medium supplemented with $10 \%(\mathrm{v} / \mathrm{v})$ fetal bovine serum (FBS) (fetal bovine serum - Cultilab, Campinas, Brazil) and antibiotic antimycotic solution (A5955 Sigma ${ }^{\circledR}$, St. Louis, MO) at $37^{\circ} \mathrm{C}$ in a 5\% CO2 atmosphere. Cells were used between the third and eighth passages.

For cytotoxicity tests, eluates from Cart1, Cart2, and Cart nHA 20 were made according to ISO 10993-12 (ISO 10993-12 Biological evaluation of medical devices - Part 12: Sample preparation and reference materials, considering the area $(1.25 \mathrm{~cm} 2)$. The materials were 
immersed in 1:1 Ham-F10 + D-MEM medium (Sigma®, St. Louis, MO) without fetal bovine serum (FBS) at $37^{\circ} \mathrm{C}$ for $24 \mathrm{~h}$, shaking at $133 \mathrm{rpm}$ in an incubator (New Brunswick Scientific - Excella E24 Incubator Shaker Series). The eluate was filtered with a syringe filter $(0.45 \square \mathrm{m})$. Four different concentrations were used $(100 \%, 75 \%, 50 \%, 25 \%)$.

\subsubsection{Cytotoxicity tests}

XTT assay. To perform these experiments CHO-K1 cells were used and the Cell Proliferation Kit II (Roche Applied Science). This test is based on the cleavage of tetrazolium salt (sodium 3'-[1-(phenylaminocarbonyl)-3,4-tetrazolium]-bis(4-methoxy-6-nitro) benzene sulfonic acid hydrate) to form an orange formazan dye. However, this conversion occurs only in viable cells due to the activity of mitochondrial dehydrogenases. Cells were seeded $(2 \times 104)$ in 24-well plates in a volume of $1 \mathrm{~mL}$ of HAM-F10: D-MEM medium (1: 1) supplemented with $10 \% \mathrm{FBS}$, and incubated at $37^{\circ} \mathrm{C}$ in a $5 \% \mathrm{CO} 224$ hours. On the following day, the cells were treated with the eluates for 24 hours. Each well was supplemented with $10 \%$ FBS. Negative controls (NC) were wells with cells and culture medium supplemented with $10 \%$ FBS in the absence of any material (untreated controls). Positive controls (PC) were wells containing CHO-K1 cells treated with doxorubicin $(3 \mu \mathrm{g} . \mathrm{mL}-1)$ for 24 hours. All treatments were carried out in duplicate. After treatment, the cultures were washed with PBS solution, and fresh medium was added. On the next day, the cultures were washed with PBS solution, and immediately $500 \mu \mathrm{L}$ of DMEM without phenol red was added, followed by the addition of 60 $\mu \mathrm{L}$ of the XTT/electron solution (50:1) (Cell Proliferation Kit II - Roche Applied Science). After $3 \mathrm{~h}$ reaction, the supernatant was transferred to a 96-well culture plate, and the absorbance was measured by a Microplate Reader (VersaMax, Molecular Devices, Sunnyvale, CA) at 492 and $690 \mathrm{~nm}$. The absorbance is directly proportional to the number of metabolically active cells (viable cells) in each treatment after $24 \mathrm{~h}$ of exposure. Cell viability was calculated from the absorbance. Three independent experiments were conducted.

Clonogenic assay. The clonogenic assay or colony formation assay is an in vitro assay based on the ability of a single cell to grow, multiply and form a colony, which is defined to be composed of at least 50 cells. Only mitotically viable cells are capable of producing progenitor cells; the number of colonies formed after treatment and an indicator of cell viability and proliferation [27]. After $24 \mathrm{~h}$ of seeding, cells ( $4 \times 104$ cells seeded) were exposed to the eluates for 24 hours. Negative controls (NC) were wells without material, and positive controls (PC) were cells treated with doxorubicin $(0.3 \mu \mathrm{g} . \mathrm{mL}-1)$ for $4 \mathrm{~h}$. All treatments were carried out in duplicate. After exposure, the cultures were washed with PBS solution, and fresh medium was added. Exponentially growing cells were seeded, after treatment, at a number of 150 cells per $25 \mathrm{~cm} 2$ culture flasks, in duplicate for each treatment. The flasks were incubated at $37{ }^{\circ} \mathrm{C}, 5 \%$ $\mathrm{CO} 2$, for 7 days without a media change. The colonies that formed were fixed with methanol: acetic acid: water (1:1:8 v/v/v) for 30 minutes and stained with Giemsa 1:20 for 20 minutes. The number of colonies counted in the NC was considered as $100 \%$. From this, the calculations of survival fractions (FS) were performed: $\mathrm{FS}=$ number of colonies counted in each treatment $\times 100 /$ Number of colonies observed in the negative. Three independent experiments were conducted. 


\subsection{Statistical analysis.}

At least 3 experiments were conducted for each analyzed parameter. The results were expressed as mean and standard error (SE). The Shapiro-Wilk test was used to assess the normality of the data and Levene's test for homogeneity. A one-way ANOVA test followed by Tukey's test was applied to the data. In addition, the data from treated groups were compared with the negative control (Dunnett's test). Graphpad Prism 5.01 was used to perform statistic tests. Differences were considered statistically significant when $\mathrm{p}<0.05$.

\section{Results and Discussion}

The viscosity results of the inks made with concentrations of $20 \%$ and $30 \%$ sodium alginate showed that both formulations were stable at room temperature for $72 \mathrm{~h}$, without undergoing organoleptic alterations or phase separation. This aspect is important to guarantee that during the manufacturing process, no variations occur in the quality and stability of the formulation.

The formulation with $20 \%$ sodium alginate presented viscosity values of around 7.8 Pa.S (77.8 and 78.1 Pa.S at the beginning and at $72 \mathrm{~h}$, respectively), which represents approximately $48 \%$ lower than the viscosity values obtained. in the formulation made with $30 \%$ sodium alginate (150.3 and $150.8 \mathrm{~Pa} . \mathrm{S}$ at the beginning, and $72 \mathrm{~h}$, respectively).

The results of the absorbed water and loss of mass determinations of the Scaffolds made with the formulations containing $20 \%$ and $30 \%$ sodium alginate was shown in Table 1.

Table 1. Results of the determination of the content of absorbed water and the loss of mass of the Scaffolds during the study of the influence of humidity.

\begin{tabular}{l|l|l} 
Scaffold & Absorbed water $(\%)$ & Loss of mass $(\%)$ \\
\hline Cart 1 & 3.92 & 13.9 \\
\hline Cart 2 & 1.17 & 12.7
\end{tabular}

The results showed that under the established working conditions, the Scaffolds made with the formulation containing $30 \%$ sodium alginate, the amount of water absorbed was less than in the Scaffolds made with the other formulation studied. On the other hand, during the study, it was observed that the loss of mass was similar in each formulation. Based on the results, the Cart 2 formulation was selected to continue or work.

Table 2 shows the results of the viscosity study of the inks made with concentrations of bacterial cellulose at $10 \%, 20 \%$, and $30 \%$, as well as the results of the determination of the hardness of the Scaffolds made with these formulations.

Table 2. Results of the viscosity study of the inks made with concentrations of bacterial cellulose at $10 \%, 20 \%$, and $30 \%$ and values of the determination of the hardness of the Scaffolds made with these formulations.

\begin{tabular}{l|l|l|l}
\multirow{2}{*}{ Formulation } & \multicolumn{2}{|l|}{ Ink viscosity $($ Pa.S $)$} & Scaffolds \\
\cline { 2 - 4 } & 0 day & 30 days & Hardness $\left(\mathbf{N} / \mathbf{m m}^{2}\right)$ \\
\hline CartnHa 10 & 149.2 & 149.1 & 490 \\
\hline CartnHa 20 & 522.4 & 521.9 & 1250 \\
\hline CartnHa 30 & 323.7 & 325.6 & 998
\end{tabular}

No variations in viscosity were observed at 30 days for any of the formulations evaluated, the ink being stable during that time. The highest viscosity values were observed in the formulation that contained $20 \%$ of bacterial cellulose, coinciding that it also showed a higher value of hardness in the scaffolds made with this formulation. 
Based on these results, the formulation containing 30\% sodium alginate and $20 \%$ bacterial cellulose was selected as the appropriate formulation to make scaffolds using the freeze-drying methodology. The amorphous calcium phosphate concentration was maintained at $50 \%$.

Once the formulation to be used was defined, a 1L batch of ink was prepared. Subsequently, the corresponding Scaffolds were elaborated and characterized.

Figure 1 shows a superficial and transversal MEV image of the scaffold made with the studied formulation. The presence of abundant porosity was observed. The qualitative analysis of EDS showed the presence of calcium, sodium, and phosphorus, which corroborates the presence of calcium phosphate and sodium alginate in the formulation.

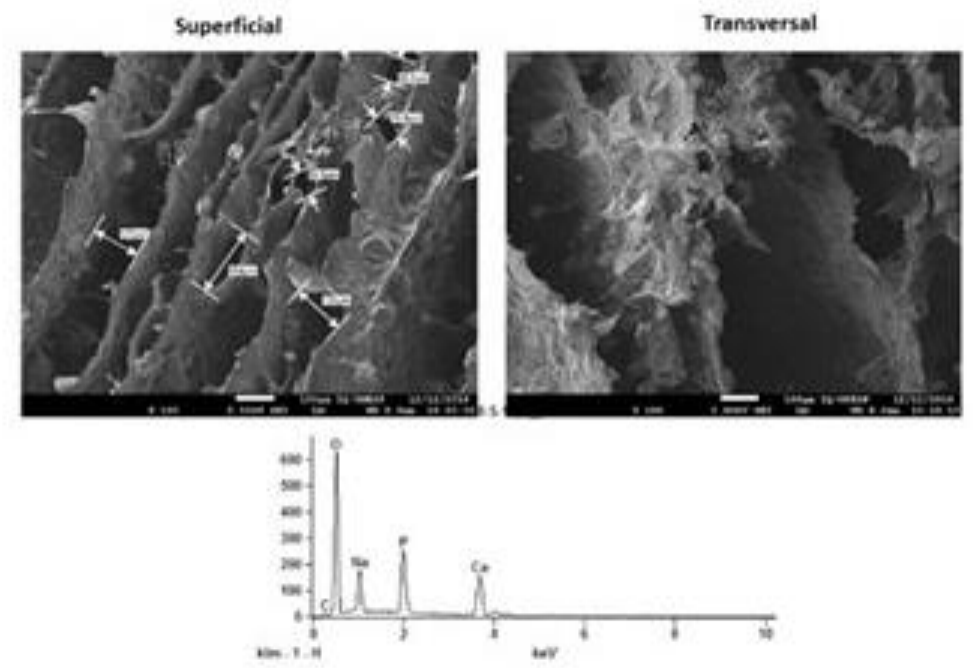

Figure 1. Superficial and transversal MEV image in 100X of scaffold made with the studied formulation and EDS analysis.

The determination of the surface area determined by BET was $39.71 \pm 0.69 \mathrm{~m}^{2} / \mathrm{g}$. The pore diameter size was in the range between $17 \AA$ and $6000 \AA$, with $39.3 \%$ of the pore diameter being over $100 \AA$. The average pore diameter was $267.33 \AA$ (equivalent to $0.027 \mu \mathrm{m}$ ).

Studies reported in the literature have recommended that the optimal porosity should be between $5 \mu \mathrm{m}$ and $100 \mu \mathrm{m}$, while the interconnectivity between the pores should be between $30 \mu \mathrm{m}$ and $50 \mu \mathrm{m}$ [10] because when the pores are smaller, cell proliferation can be affected because mobility and penetration within the Scaffolds would be difficult. On the other hand, pores with very large dimensions, create space that makes it difficult to contact cells with a pore surface, which can cause cell death.

It is also known that the great difficulty of conventional methods, such as that used in this work to elaborate scaffolds, lies in difficulty in controlling the size of the pores, which justifies that the mean values of the pore size achieved in this work are below the recommended values in the literature [12],

The results of the test of the compressive strength in the sample showed that the scaffold undergoes a process of deformation after the rupture of the piece. This phenomenon is caused by the presence of polymers (sodium alginate and cellulose bacterial) in the formulation. It has been reported that during the application of a load at a constant speed, the polymers respond efficiently to tension applied, absorbing energy, and dissipating it, will cause cracks in the piece [28], The compressive strengths of the samples were $66.76 \pm 0.09 \mathrm{MPa}$.

MEV (Figure 2) of the samples before performing the compression test shows the morphology of layers in leaf forms, with abundant pores. This morphology changes after 
carrying out the test, observing a decrease in the size of the pores and a deformity in the structure of the sample.

\subsection{Cytotoxicity test.}

As part of the biological studies, the cytotoxicity of the Scaffold Cart 1 and Cart 2 was evaluated, as well as the scaffold CartnHa 20.
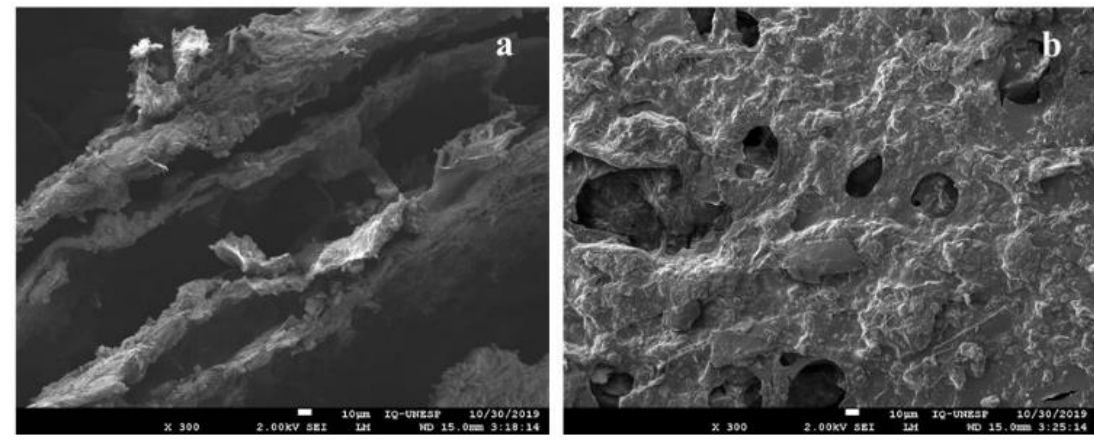

Figure 2. MEV of the sample before (a) and after (b) performing the compression test.

\subsection{XTT assay.}

Figure 3 shows the mean and standard error (mean \pm SE) for cell viability obtained by XTT assay for Cart 1 and Cart 2 eluates. Figure 4 presents CartnHa 20 XTT results. Cell viability is related to the absorbance, and Negative Control (NC) was considered as $100 \%$ cell viability.

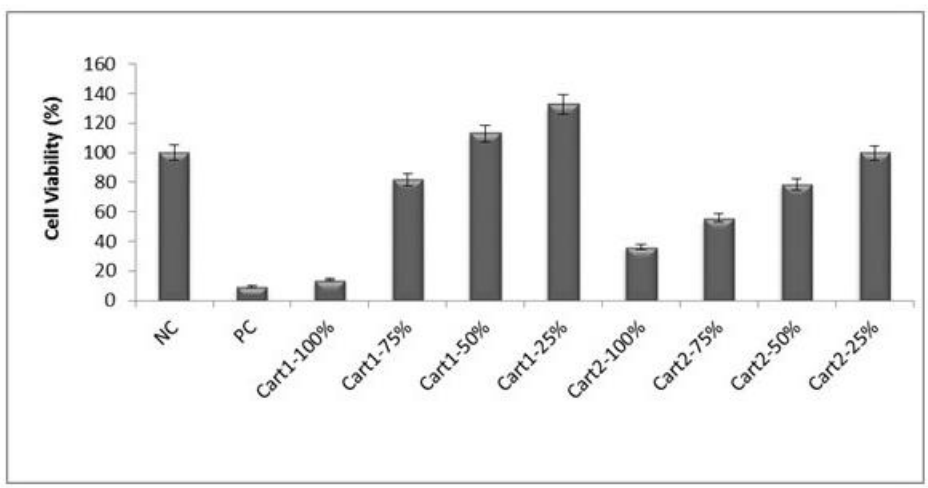

Figure 3. Cytotoxicity (cell viability) assessed by XTT assay. Columns indicate the mean value of cell viability. NC was considered $100 \%$ cell viability. Bars indicate the standard error. $* * *=p<0.0001, * *=p<0.001, *=$ $\mathrm{p}<0.05$ in relation to NC. Dunnett's test.

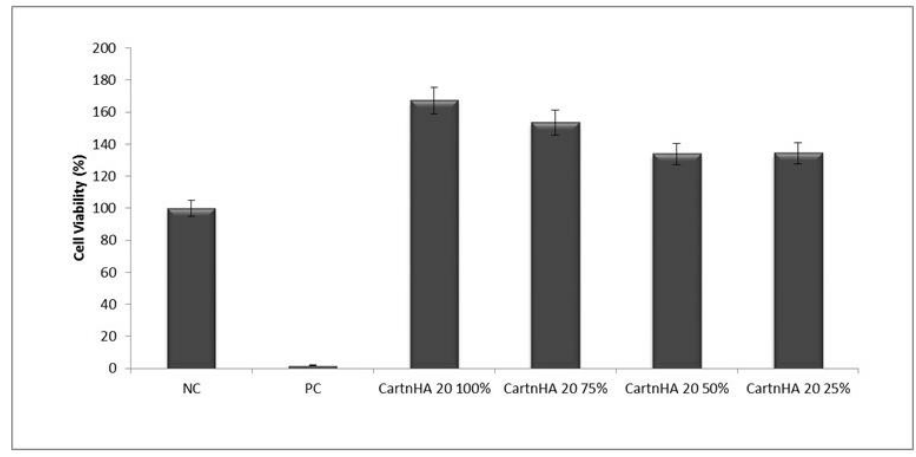

Figure 4. Cytotoxicity (cell viability) assessed by XTT assay. Columns indicate the mean value of cell viability. NC was considered $100 \%$ cell viability. Bars indicate the standard error. $* * *=p<0.0001, * *=p<0.001, *=$ $\mathrm{p}<0.05$ in relation to NC. Dunnett's test. 
Cart1-100\% revealed a high cytotoxic effect compared to NC ( $<<0.0001$; Dunnett's). No cytotoxic effects were verified in Cart 1 75\%, 50\%, and 25\%. Cart2-25\% presented no statistically significant difference compared to NC. Although Cart2 100\%, 75\%, and 50\% decreased cell viability.

If we consider the score of cell viability according to the method of Sjogren et al. and Atay et al. [29, 30], if cell viability exceeded 90\%, the material was deemed non-cytotoxic. For cell viability at $60-90 \%$ range, the material was regarded as slightly cytotoxic. For cell viability at $30-59 \%$ range, the material was regarded as moderately cytotoxic. For cell viability below $30 \%$, the material was considered severely cytotoxic. The concentrations of $100 \%$ and $75 \%$ of Cart 2 were moderately cytotoxic (36\% and 56\%, respectively), and Cart $250 \%$ was slightly cytotoxic $(79 \%)$.

CartnHa 20 did not present cytotoxicity by XTT assay. On the contrary, wells treated with the CartnHa 20 eluates demonstrated greater cell viability compared to NC. The highest eluate concentrations increased cell viability (Figure 4).

\subsection{Clonogenic assay.}

Figure 5 presents the mean and standard error (mean $\pm \mathrm{SE}$ ) for the surviving fraction obtained by clonogenic assay for Cart1 and Cart2 eluates. Negative Control (NC) was considered as $100 \%$ surviving fraction.

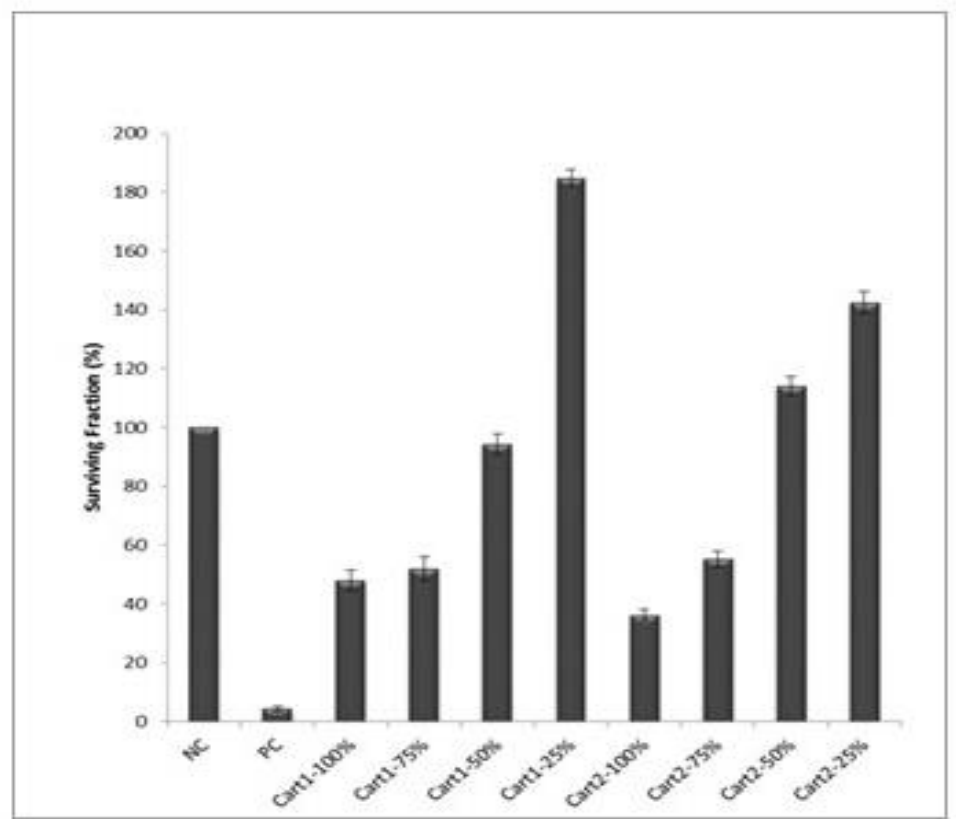

Figure 5. Cytotoxicity (cell's proliferation capacity) assessed by Clonogenic assay. Columns indicate the mean value of the surviving fraction. NC was considered a 100\% surviving fraction (100\% of the proliferation capacity of the cells). Bars indicate the standard error. $* * *=p<0.0001$ in relation to NC. Dunnett's test.

Clonogenic assays, or colony formation assays, measure clonogenic potential, i.e., the proliferative ability of single cells to form a colony [31], Besides colony formation, this assay measures cell survival and is routinely used as a sensitive model for assessing long-term cytotoxicity.

Cart1-100\%, Cart1-75\%, Cart2-100\%, and Cart2-75\% presented surviving fraction values statistically different compared to $\mathrm{NC}(\mathrm{p}<0.0001$; Dunnett's), indicating a compromise in the proliferative capacity of the cells. 
It was verified that the cell surviving fraction of Cart1-50\% was similar to $\mathrm{NC}(\mathrm{p}>0.05$; Dunnett's). Cart1-25\%, Cart2-50\%, and Cart2-25\% presented a significant increase in the proliferative capacity of the CHO-K1 cells compared to $\mathrm{NC}$ ( $\mathrm{p}<0.0001$; Dunnett's).

XTT cell viability assay shows the immediate cytotoxic effect on the cells, while the clonogenic assay shows if other damages may have occurred to cells that stop their proliferative capacity at a later time. According to Saotome et al. [32], a single in vitro experiment shows only one aspect of the action of chemicals. Because of this, a short-term cytotoxicity method (XTT) and a long-term cytotoxicity test (Clonogenic assay) were made.

Analyzing together the two cytotoxicity tests (XTT and Clonogenic Survival), it can be observed agreement in the results of both tests regarding the concentrations of Cart1 eluates. The lower concentrations (50\% and 25\%) were not cytotoxic. Besides, Cart1-25\% increased cell viability and improved the proliferative capacity of the cells. Similar results were observed in Cart 2 eluates. The lower concentrations showed the best responses related to cytotoxicity. Although Cart2-50\% slightly decreased the cell viability (XTT), it did not promote late cytotoxicity (clonogenic assay). On the contrary, it increased the proliferative capacity of the cells by $14 \%$ compared to NC. Cart $2-25 \%$ presented similar cell viability (XTT) compared to $\mathrm{NC}$, and increased the proliferative capacity of the cells by $43 \%$.

It can be concluded that the lower concentrations of Cart1 and Cart2 presented no cytotoxic effects in $\mathrm{CHO}-\mathrm{K} 1$ cells, and increased the cell viability and the proliferative capacity of the cells. CartnHa 20 presented no cytotoxicity. On the contrary, it promoted high cell viability.

\section{Conclusions}

The results of this work demonstrated the feasibility of Scaffolds elaboration, applying the freeze-drying methodology. The formulation that presented the best results was the one that contained amorphous calcium phosphate (50\%), bacterial cellulose gel (20\%), and sodium alginate $(30 \%)$. Cytotoxicity studies showed that the studied formulation did not present cytotoxicity, promoting cell viability.

\section{Funding}

This research was funded by the Coordination for the Improvement of Higher Education Personnel (CAPES) (CAPES-MES project 186/13) and The São Paulo Research Foundation FAPESP (project 2017 / 15487-3)

\section{Acknowledgments}

The authors thank Products Biotechnological LTDA, São Carlos - São Paulo, Brazil, for the support needed to carry out this work.

\section{Conflicts of Interest}

The authors declare no conflict of interest.

\section{References}

1. McNamara, S.L.; Rnjak-Kovacina, J.; Schmidt, D.F.; Lo, T.J.; Kaplan, D.L. Silk as a biocohesive sacrificial binder in the fabrication of hydroxyapatite load bearing scaffolds. Biomaterials 2014, 35, 6941-6953, https://doi.org/10.1016/j.biomaterials.2014.05.013. 
2. Golchin, A.; Farahany, T.Z. Biological Products: Cellular Therapy and FDA Approved Products. Stem Cell Reviews and Reports 2019, 15, 166-175, https://doi.org/10.1007/s12015-018-9866-1.

3. Golchin, A.; Shams, F.; Kangari, P.; Azari, A.; Hosseinzadeh, S. Regenerative Medicine: Injectable CellBased Therapeutics and Approved Products. Adv Exp Med Biol. 2020, 1237, 75-95, https://doi.org/10.1007/5584_2019_412.

4. Moreno, M.S. Engenharia de Tecidos na substituição de tecido ósseo. Dissertação (Mestrado). Universidade Fernando Pessoa, Porto, 2014.

5. Dai, Z.; Ronholm, J.; Tian, Y.; Sethi, B.; Cao, X. Sterilization techniques for biodegradable scaffolds in tissue engineering applications. Journal of Tissue Engineering 2016, 7, https://doi.org/10.1177/2041731416648810.

6. Fernandez-Yague, M.A.; Abbah, S.A.; McNamara, L.; Zeugolis, D.I.; Pandit, A.; Biggs, M.J. Biomimetic approaches in bone tissue engineering: Integrating biological and physicomechanical strategies. Advanced Drug Delivery Reviews 2015, 84, 1-29, https://doi.org/10.1016/j.addr.2014.09.005.

7. Gautam, S.; Dinda, A.K.; Mishra, N.C. Fabrication and characterization of PCL/gelatin composite nanofibrous scaffold for tissue engineering applications by electrospinning method. Materials Science and Engineering: C 2013, 33, 1228-1235, https://doi.org/10.1016/j.msec.2012.12.015.

8. Kang, H.W.; Tabata, Y.; Ikada, Y. Fabrication of porous gelatin scaffolds for tissue engineering. Biomaterials 1999, 20, 1339-1344, https://doi.org/10.1016/s0142-9612(99)00036-8.

9. Han, J.; Zhou, Z.; Yin, R.; Yang, D.; Nie, J. Alginate-chitosan/hydroxyapatite polyelectrolyte complex porous scaffolds: Preparation and characterization. International Journal of Biological Macromolecules 2010, 46, 199-205, https://doi.org/10.1016/j.ijbiomac.2009.11.004.

10. Rebelo, M.; Chaud, M.; Balcão, V.; Vila, M.; Aranha, N.; Hanai-Yoshida, V.; Alves, T.; Oliveira Jr, J. Chitosan-based scaffolds for tissue regeneration: Preparation and microstructure characterisation. European Journal of Biomedical and Pharmaceutical Sciences 2016, 3, 15-24.

11. Lastra, M.L. Desarrollo de estrategias de ingeniería de tejidos para la regeneración osteo-cartilaginosa. Tesis Doctoral. Universidad Nacional de la Plata. La Plata. 2018.

12. Irsen, S.; Seitz, H.; Tille, C.; Bermes, G.; Wolfinger, E.; Sader, R.; Zeilhofer, H.F. Anatomical rapid prototyping models with soft and hard tissue representation for surgical planning. Technology and Health Care 2004, 12, 110-111.

13. Lv, Q.; Feng, Q. Preparation of 3-D regenerated fibroin scaffolds with freeze drying method and freeze drying/foaming technique. Journal of Materials Science: Materials in Medicine 2006, 17, 1349-1356, https://doi.org/10.1007/s10856-006-0610-z.

14. Babilotte, J.; Guduric, V.; Le Nihouannen, D.; Naveau, A.; Fricain, J.-C.; Catros, S. 3D printed polymermineral composite biomaterials for bone tissue engineering: Fabrication and characterization. Journal of Biomedical Materials Research Part B: Applied Biomaterials 2019, 107, 2579-2595, https://doi.org/10.1002/jbm.b.34348.

15. Zhou, W.; Qiao, Z.; Nazarzadeh Zare, E.; Huang, J.; Zheng, X.; Sun, X.; Shao, M.; Wang, H.; Wang, X.; Chen, D.; Zheng, J.; Fang, S.; Michael Li, Y.; Zhang, X.; Yang, L.; Makvandi, P.; Wu, A. 4D-Printed Dynamic Materials in Biomedical Applications: Chemistry, Challenges, and Their Future Perspectives in the Clinical Sector. Journal of Medicinal Chemistry 2019, 30, 1172-1187, https://doi.org/10.1080/09205063.2019.1623989.

16. Dattola, E.; Parrotta, E.I.; Scalise, S.; Perozziello, G.; Limongi, T.; Candeloro, P.; Coluccio, M.L.; Maletta, C.; Bruno, L.; De Angelis, M.T.; Santamaria, G.; Mollace, V.; Lamanna, E.; Di Fabrizio, E.; Cuda, G. Development of 3D PVA scaffolds for cardiac tissue engineering and cell screening applications. RSC Advances 2019, 9, 4246-4257, https://doi.org/10.1039/C8RA08187E.

17. Samourides, A.; Browning, L.; Hearnden, V.; Chen, B. The effect of porous structure on the cell proliferation, tissue ingrowth and angiogenic properties of poly(glycerol sebacate urethane) scaffolds. Materials Science and Engineering: C 2020, 108, https://doi.org/10.1016/j.msec.2019.110384.

18. Piazza, R.D.; Pelizaro, T.A.G.; Rodriguez-Chanfrau, J.E.; La Serna, A.A.; Veranes-Pantoja, Y.; Guastaldi, A.C. Calcium phosphates nanoparticles: The effect of freeze-drying on particle size reduction. Materials Chemistry and Physics 2020, 239,https://doi.org/10.1016/j.matchemphys.2019.122004.

19. Rodriguez-Chanfrau, J.E.; Garcia Pelizaro, T.A.; da Silva, R.M.; Tolaba, A.G.; Pizoni, E.; Veranes-Pantoja, Y.; Guastaldi, A.C. Synthesis by Wet Chemical Method of Different Phases of Apatites Applying Ultrasound. Journal of Bionanoscience 2018, 12, 134-141, https://doi.org/10.1166/jbns.2018.1502.

20. Garcia Pelizaro, T.A.; Tolaba, A.G.; Rodriguez-Chanfrau, J.E.; Veranes-Pantoja, Y.; Guastaldi, A.C. Influence of the Application of Ultrasound During the Synthesis of Calcium Phosphates. Journal of Bionanoscience 2018, 12, 733-738, https://doi.org/10.1166/jbns.2018.1585.

21. Tolaba, A.G.; Pellizaro, T.A.G.; Rodriguez-Chanfrau, J.E.; Guastaldi, A.C. Statistical evaluation of the effect of ultrasound on the synthesis of calcium phosphates. Biointerface Research in Applied Chemistry 2019, 9, 4343-4348.

22. Rodriguez Chanfrau, J.E.; Veranes Pantoja, Y.; Guastaldi, A.C. Ultrasonic application and spray drying during amorphous calcium phosphate synthesis. Letters in Applied NanoBioScience 2019, 8, 711-714, https://doi.org/10.33263/LIANBS84.711714. 
23. Rodriguez-Chanfrau, J.E.; Veranes-Pantoja, Y.; Basmaji, P.; Guastaldi, A.C. Influence of the reaction time during the treatment of bacterial cellulose with sulfuric acid solution. Biointerface Research in Applied Chemistry 2019, 9, 4301-4304, https://doi.org/10.33263/BRIAC95.301304.

24. Chanfrau, R.; Santos, M.; Riccardi, C.; Molina de Olyveira, G.; Hernández Escalona, M.; Basmaji, P.; Veranes Pantoja, Y.; Carlos, G. Chemical modification of bacterial cellulose for use in regenerative medicine. Cellulose Chemistry and Technology 2017, 51, 673-680.

25. Chanfrau, R.; Molina de Olyveira, G.; Santos, M.; Basmaji, P.; Veranes Pantoja, Y.; Carlos, G. Bacterial cellulose hydrogel treated with phosphoric acid for used as biomaterial on bone tissue regeneration. Advance Pharmaceutical Journal 2017, 1, 133-138.

26. Sandini Oleaga, I. Andamios porosos. Tesis Doctoral. Universidad del Pais Vasco. Portugalete. 2015.

27. Franken, N.A.P.; Rodermond, H.M.; Stap, J.; Haveman, J.; van Bree, C. Clonogenic assay of cells in vitro. Nature Protocols 2006, 1, 2315-2319, https://doi.org/10.1038/nprot.2006.339.

28. Sundaram, J.; Durance, T.D. Influence of Processing Methods on Mechanical and Structural Characteristics of Vacuum Microwave Dried Biopolymer Foams. Food and Bioproducts Processing 2007, 85, 264-272, https://doi.org/10.1205/fbp07012.

29. Sjögren, G.; Sletten, G.; Dahl, J.E. cytotoxicity of dental alloys, metals, and ceramics assessed by Millipore filter, agar overlay, and MTT tests. Journal of Prosthetic Dentistry 2000, 84, 229-236, https://doi.org/10.1067/mpr.2000.107227.

30. Atay, A.; Bozok Cetintas, V.; Cal, E.; Kosova, B.; Kesercioglu, A.; Guneri, P. Cytotoxicity of hard and soft denture lining materials. Dental Materials Journal 2012, 31, 1082-1086, https://doi.org/10.4012/dmj.2012209.

31. Yalkinoglu, A.O.; Schlehofer, J.R.; zur Hausen, H. Inhibition of N-methyl-N'-nitro-N-nitrosoguanidineinduced methotrexate and adriamycin resistance in CHO cells by adeno-associated virus type 2 . Int J Cancer 1990, 45, 1195-1203, https://doi.org/10.1002/ijc.2910450634.

32. Saotome, K.; Morita, H.; Umeda, M. Cytotoxicity test with simplified crystal violet staining method using microtitre plates and its application to injection drugs. Toxicology in Vitro 1989, 3, 317-321, https://doi.org/10.1016/0887-2333(89)90039-8. 